\title{
Organic Manure Amended with Phosphate Solubilizing Bacteria on Soil Phosphorous Availability
}

\author{
B. C. Walpola ${ }^{1^{*}}$ and R. H. A. N. Hettiarachchi ${ }^{1}$ \\ Date Received: 07 $7^{\text {th }}$ February 2019 / Date Accepted: 10 $0^{\text {th }}$ April 2019
}

\begin{abstract}
Purpose : Combine use of phosphate solubilizing microorganisms and organic manure has greater agronomic utility as it could improve phosphorous $(P)$ utilization efficiency through conversion of insoluble $P$ to accessible forms. Therefore, the present study was conducted to assess the effect of different organic manures (poultry manure, goat manure and cow dung) with phosphate solubilizing microorganism on phosphorous availability.
\end{abstract}

Research Method : The phosphate solubilizing bacterial (PSB) strain employed in this study was isolated from soil samples collected from agricultural lands in Matara District of Sothern Sri Lanka. The strain was identified as Enterobacter cancerogenous. Eight treatment combinations each replicated three times were used in the study.

Findings : $P$ availability of organic manure amended soils was progressively increased irrespectively the inoculation of PSB strain. The bulk of the increment occurred during the first 2 to 3 weeks of the incubation followed by slight reductions at the later stages. $P$ availability of the soil amended with organic manures was significantly $(P \leq 0.05)$ higher than that of the control. Furthermore, the specified were much higher when PSB was inoculated to the soil amended with organic manures. PSB inoculants were used with poultry manure showed the highest $P$ availability.

Originality/Value: The availability of soil phosphorous is enhanced by combine use of organic manures and PSB inoculants; the practice is suggested to be employed in integrated nutrient management strategies.

Keywords: Enterobacter cancerogenous, Organic manure, Phosphate solubilizing bacteria

\section{INTRODUCTION}

Phosphorus $(\mathrm{P})$ nutrition is considered as one of the primary factors limiting crop yields (Zaidi et al., 2009). The total P levels of soils usually range between $0.02-0.5 \%$, of which only around $0.1 \%$ is available to plants. Therefore, continuous application of phosphotic fertilizers is essential to maximize crop yields. However, more than $80 \%$ of the applied phosphotic fertilizers get readily fixed to soil components and become unavailable to plants by forming complexes such as aluminum phosphate and iron phosphate in acidic soils and calcium phosphates in calcareous soils. Therefore, the recovery efficiency of phosphorous is less than $20 \%$ from applied and native soil phosphorous (Walpola and Yoon, 2012). Hence, seeking for viable solutions to enhance the recovery efficiency and solubility of applied and native phosphorous gains increased attention.

Conversion of insoluble phosphate complexes to soluble forms by phosphate solubilizing microorganisms through production of organic acids such as acetate, lactate, oxalate, tartarate, succinate, citrate, gluconate, ketogluconate and glycolate has been observed in media supplemented with insoluble phosphate sources (Fankemetal.,2006; Hu etal.,2006).Availability and solubility of phosphorous from applied and native phosphorous could be accelerated by

\footnotetext{
${ }^{I^{*}}$ Department of Soil Science, Faculty of Agriculture, University of Ruhuna.

bcwalpola@soil.ruh.ac.lk
}

DD ORCID http://orcid.org/0000-0002-4663-0943 
applying different organic amendments such as animal manure, plant residues and green manure (Imran et al., 2011; Adesanwo et al., 2012;Abbasi et al., 2015), composts (Nishanth and Biswas, 2008; Wickramatilake et al., 2010). Acidic environment generated by the decomposition process of organic amendments enhances the availability and solubility of applied phosphorous (Nishanth and Biswas, 2008). Therefore, the incorporation of organic manure to soils is considered to be a possible means of increasing recovery efficiency and solubility of applied and native phosphorous. The abundance of soil microorganisms is high in soils amended with different types of organic manure. This may help to solubilize insoluble phosphorous and increase phosphorous availability to the plants (Hu et al., 2006).

Combined use of organic manure and phosphate solubilizing bacteria could enhance phosphorous solubilization which in turn would increase the availability of phosphorous to plants. Therefore, the activation of phosphate solubilizing microorganisms and solubilization of insoluble phosphates through the production of organic acids could be expected to occur in soils that are amended with organic manure.

Use of phosphate solubilizing microorganisms such as Pseudomans, Bacillus, Enterobacter, Azospirillum and Rhizobium etc. to solubilize insoluble phosphates has a greater agronomic utility to compensate high cost of phosphatic fertilizer application/production. Such measures could have positive impacts on the environment as well. Consequently, the present study was conducted to assess the effect of poultry manure, goat manure and cow dung amended with phosphate solubilizing microorganisms on phosphorous availability of soil.

\section{MATERIALS AND METHODS}

\section{Isolation of phosphate solubilizing bacterial strains}

Rhizosphere soil samples collected from agricultural lands in Matara district of Sothern Sri Lanka were employed in isolating phosphate solubilizing bacterial strains. In the laboratory, $10 \mathrm{~g}$ of moist soil from each sample were weighed and transferred to $250 \mathrm{ml}$ Erlenmeyerflask containing sterilized $90 \mathrm{ml}$ of $0.85 \% \mathrm{NaCl}$ solution. The suspension was then shaken for 30 minutes at approximately 150 rpm. Immediately after shaking, a series of tenfold dilutions of the suspension was made by pipetting $1 \mathrm{ml}$ aliquot into sterilized 9 $\mathrm{ml}$ of $0.85 \% \mathrm{NaCl}$ solution. Serial dilutions were prepared using dilution plate technique (Wollum II, 1982). Each dilution was plated in the National Botanical Research Institute Phosphorus (NBRIP) agar plates containing $16 \mathrm{~g}$ agar, $10 \mathrm{~g}$ glucose, $5 \mathrm{~g} \mathrm{Ca}_{3}\left(\mathrm{PO}_{4}\right)_{2}, 5 \mathrm{~g}$ $\mathrm{MgCl}_{2} \cdot 6 \mathrm{H}_{2} \mathrm{O}, 0.25 \mathrm{~g} \mathrm{MgSO}_{4} \cdot 7 \mathrm{H}_{2} \mathrm{O}, 0.2 \mathrm{~g} \mathrm{KCl}$, $0.1 \mathrm{~g}\left(\mathrm{NH}_{4}\right)_{2} \mathrm{SO}_{4}$ in $1 \mathrm{~L}$ distilled water. The $\mathrm{pH}$ of the media was adjusted to 7 using $\mathrm{HCl}$. The plates were incubated 4-5 days in an incubator at $30^{\circ} \mathrm{C}$. The colonies with clear halos were considered as phosphate solubilizing colonies (Gyaneshwar et al., 1999). They were further purified by re-streaking on the fresh NBRIP agar plates at $30^{\circ} \mathrm{C}$. Bacterial strains which exhibited clear zones on the agar plates were selected as phosphate solubilizing organisms.A total of 15 phosphate solubilizing bacterial strains were isolated and maintained on $30 \%$ glycerol stock until use. The bacterial strain which exhibited the largest halo on NBRIP agar plates was selected for further studies.

\section{Phosphate solubilization under in vitro conditions}

The selected bacterial strain was allowed to grow in sterilized liquid NBRIP medium (20 $\mathrm{ml})$ at $30^{\circ} \mathrm{C}$ for 2 days with continuous shaking at $150 \mathrm{rpm}$. Aliquots of culture $(1 \mathrm{ml})$ were then transferred to $500 \mathrm{ml}$ flasks ( $\mathrm{n}=3$ per strain) containing sterilized liquid NBRIP medium (200 $\mathrm{ml}$ ) and incubated for 7 days with continuous shaking at $30^{\circ} \mathrm{C}$. Sterilized medium without the bacterial strain served as the control. A sample $(10 \mathrm{ml})$ of each cultured and control were taken daily and centrifuged at $10000 \mathrm{rpm}$ for $15 \mathrm{~min}$. The clear supernatant was used in determining the amount of phosphorous released into the medium. The $\mathrm{pH}$ of the culture medium was also recorded with the $\mathrm{pH}$ meter equipped with glass electrode. The phosphorus availability 
was determined using phospho-molybdate blue color method (Murphy and Riley, 1962).

16S rDNA gene sequencing and Phylogenetic analysis of the isolated bacterial strain

The partial sequencing of $16 \mathrm{~S}$ rRNA for the bacterial strains was done with the help of DNA sequencing service, SOLGENT, Daejeon, South Korea using universal primers, 27F (5'-AGAGTTTGATCCTGGCT CAG-3') and 1492R (5'-GGTTACCTTGTTACGACTT-3'). The online program BLAST was used in identifying the related sequences with known taxonomic information available at the data Information - NCBI (http://www.ncbi.nlm. nih.gov/BLAST). A Phylogenetic tree was constructed using CLUSTAL Xprogram (Thompson et al., 1997), which involved sequence alignment by neighbor joining method (Saitou and Nei,1987) and maximum parsimony using the MEGA4 program (Kumar et al., 2001). Grouping of sequences was based on confidence values obtained by bootstrap analysis of1,000 replicates. Gaps were edited in the Bio Edit program and evolutionary distances were calculated using Kimuratwo parameter model. Reference sequences were retrieved from GenBank under the accession numbers indicated in the trees. bank of National Centre for Biotechnology

\section{Soil used for the pot experiment}

Soil belongs to Red Yellow Podzolic great soil group and classified as Hapludults according to the USDA soil taxonomy (Mapa et al., 1999) were collected randomly from research farm, Faculty of Agriculture, University of Ruhuna, Mapalana, Kamburupitiya, Sri Lanka. After removing the surface litter, soil samples were taken from $0-15 \mathrm{~cm}$ depth using an auger and mixed thoroughly to make composite samples. The soil was then passed through a $2 \mathrm{~mm}$ sieve to eliminate coarse rock and plant material. A subsample was taken, air dried and used for the determination of physico- chemical characteristics of soil (Table 01).

\section{Organic manures}

Poultry manure - PM, goat manure - GM and cow dung - CD) used in this study were collected from the Faculty farm, Faculty of Agriculture, University of Ruhuna, Mapalana, Kamburupitiya, Sri Lanka. Composite samples of well dried manure was taken, crushed into smaller particles by hand pressing, homogenized and passed through a $1 \mathrm{~mm}$ sieve before use. Total nitrogen in manure samples were determined by the Kjeldahl method and the total phosphorous content was determined by vanadomolybdate yellow color using spectrophotometer (Table 02).

Table 01: Some important physico-chemical properties of soil used in incubation study

\begin{tabular}{cc}
\hline Soil properties & Value \\
\hline Sand (\%) & $84 \pm 1.25$ \\
Silt (\%) & $12 \pm 0.48$ \\
Clay (\%) & $4 \pm 0.85$ \\
Soil texture & Loamy sand \\
Bulk density $\left(\mathrm{g} / \mathrm{cm}^{3-}\right)$ & $1.28 \pm 0.23$ \\
$\mathrm{pH}$ & $6.43 \pm 0.54$ \\
Organic carbon $(\%)$ & $0.85 \pm 0.18$ \\
Total $\mathrm{N}(\%)$ & $0.15 \pm 0.02$ \\
$\mathrm{NH}_{4}^{+}-\mathrm{N}(\mathrm{mg} / \mathrm{kg}$ soil) & $82 \pm 2.12$ \\
$\mathrm{NO}_{3}^{-}-\mathrm{N}(\mathrm{mg} / \mathrm{kg}$ soil $)$ & $31 \pm 1.63$ \\
Available $\mathrm{P}(\mathrm{mg} / \mathrm{kg}$ soil $)$ & $48 \pm 2.15$ \\
Available $\mathrm{K}(\mathrm{mg} / \mathrm{kg}$ soil $)$ & $118 \pm 6.55$ \\
$\mathrm{CEC}\left(\mathrm{cmol}^{(+)} / \mathrm{kg}\right.$ soil & $12.1 \pm 0.25$ \\
\hline
\end{tabular}


Table 02: Chemical composition of organic manure used for the experiment

\begin{tabular}{cccc}
\hline Organic manure & Organic C $(\%)$ & $\mathrm{N}(\%)$ & $\mathrm{P}(\%)$ \\
\hline Poultry manure & $18.53 \pm 0.31$ & $2.21 \pm 0.13$ & $2.95 \pm 0.12$ \\
Goat manure & $16.24 \pm 0.22$ & $1.85 \pm 0.09$ & $0.68 \pm 0.07$ \\
Cow dung & $15.64 \pm 023$ & $1.42 \pm 0.11$ & $0.72 \pm 0.04$ \\
\hline
\end{tabular}

\section{Inoculum preparation for incubation study}

A Single colony of isolated bacterial strain was transferred to $500 \mathrm{ml}$ flask containing nutrient broth. The Colony was then grown aerobically in flask on a rotating shaker $(150 \mathrm{rpm})$ for $48 \mathrm{~h}$ at $30^{\circ} \mathrm{C}$. The bacterial suspension was then diluted in sterile distilled water to a final concentration of $10^{8} \mathrm{CFU} \mathrm{ml^{-1 }}$ and resulting suspension was used as inoculums for the pot experiment.

\section{Incubation study}

Plastic pots ( $25 \mathrm{~cm}$ in diameter, $35 \mathrm{~cm}$ in height) were filled with the soil mentioned above and moisture content of soil was adjusted to $60 \%$ of water holding capacity (WHC) by adding water. They were then kept in dark for one week prior to addition of organic manure for pre-incubation. After pre-incubation period, addition of organic manure was done on the base of the recommended mulch application rate of 5 tons dry matter per hectare, assuming that top $15 \mathrm{~cm}$ of 1 ha land contains $2.31 \times 10^{6}$ $\mathrm{kg}$ of soil (bulk density of the soil $1.542 \mathrm{gcm}^{-3}$ ). Accordingly, $10 \mathrm{ml}$ of bacterial suspension was inoculated into the middle part of the pots. The control pots received $10 \mathrm{ml}$ of diluted LB broth with no bacteria. Following the addition of all amendments, the soil was thoroughly mixed and the weight of each pot was recorded. Pots were covered with black polythene which was perforated with a needle to ensure natural gas exchange.

The pots were then arranged in a completely randomized block design with three replications per treatment. The experimental plan was based on eight treatments as follows; (1) soil without PSB or organic manure-control; (2) soil + poultry manure; (3) soil + goat manure; (4) soil + cow dung; (5) soil + poultry manure + PSB; (6) soil + goat manure + PSB; (7) soil
+ cow dung + PSB; (8) soil + PSB.All the amended pots along with the controls that were incubated in the dark at room temperature (30 $\pm 1^{\circ} \mathrm{C}$ ). Constant moisture content of the soil was maintained by daily monitoring and adding distilled water when necessary.

\section{Soil analysis}

Samples of all treated and controls incubated for different time intervals were analyzed for changes in soil-available $\mathrm{P}$ and $\mathrm{pH}$. Triplicate samples from each treatment including control were taken at $7,14,21$, $28,35,42$ and 56 days of incubation and analyzed for available P. The soil-available $P$ was measured by ammoniummolybdate blue color method (Murphy and Riley, 1962) using a spectrophotometer. At each sampling time, $10 \mathrm{~g}$ soil from each pot was taken and used for measuring the changes in $\mathrm{pH}$ using a glass electrode in a $1: 2.5(\mathrm{v}=\mathrm{v})$ soil-water suspension.

\section{Statistical analysis}

All data from the incubation experiment were subjected to analysis of variance (ANOVA) using SAS package (SAS, 1999). The Duncan's Multiple Range Test (DMRT) was applied to test the significance of treatment means at $\mathrm{P}$ $\leq 0.05$. Values were given as means \pm SD for triplicate samples.

\section{RESULTS AND DISCUSSION}

\section{Isolation and identification of phosphate solubilizing bacterial strains}

A total of 15 bacterial isolates that exhibited clear zones on the agar plates were selected as phosphate solubilizing bacterial isolates (Figure 
01). The most efficient phosphate solubilizing bacteria (PSB-1) was selected for further studies. The selected strain had a marked insoluble phosphate solubilizing ability as visualized by the clear zone development around the colonies after incubation. According to $16 \mathrm{~S}$ rRNA sequence analysis, the strain was identified as Enterobacter cancerogenous(PSB-1). Comparison of the16S rRNA sequence among available strains of Enterobacter species closely associated Enterobacter cancerogenus $L M G$ 2693with $99.2 \%$ identity. The neighborjoining method was employed to construct the phylogenetic tree which illustrates the relationships of $16 \mathrm{~S}$ rRNA strain sequence and other Enterobacter species (Figure 02). A sequence of the Enterobacter cancerogenus $L M G 2693$ was deposited in the GenBank nucleotide sequence data library under KX815170 accession number.

\section{Phosphate solubilization under in vitro conditions}

An inoculant is a complex biological formulation that combines two elements: cultured microorganisms and compounds secreted into their growth medium under controlled conditions. Changes in $\mathrm{pH}$ of NBRIP medium and soluble $\mathrm{P}$ content, released from inorganic $\mathrm{P}$, due to the addition of bacterial inoculants are shown in Figure 03. A significant $(\mathrm{P} \leq 0.05)$ increment in soluble $\mathrm{P}$ content was observed with PSB inoculation. A significant reduction in the $\mathrm{pH}$ of the PSB-inoculated medium was also observed as compared with the control where it remained constant $(\mathrm{pH} 7)$. A strong negative correlation $(r=-0.934 \pm 0.1, P \leq 0.05)$ could be observed between phosphate solubilization and $\mathrm{pH}$.

\section{Phosphate solubilization under invivo conditions}

The effect of different organic amendments with and without phosphate solubilizing bacterial strain on changes in soil $\mathrm{pH}$ over 8 weeks of incubation is presented in Table 03 and the overall effect of different organic amendments on soil pH change is presented in Figure 04. Soil $\mathrm{pH}$ was significantly decreased $(\mathrm{P} \leq 0.05)$ in all treatments throughout the incubation period except control. The reduction of $\mathrm{pH}$ was rapid during the initial stages of incubation (first 2 to 3 weeks of incubation) followed by slower decrease. However, some fluctuations in $\mathrm{pH}$ were observed from some treatments. A significant decrease $(\mathrm{P} \leq 0.05)$ in soil $\mathrm{pH}$ was recorded from PSB inoculated soils than the un-inoculated soils. The $\mathrm{pH}$ of the initial soil was 6.43 , which subsequently decreased down to $5.85,5.95$ and 5.96 at the end of the incubation period respectively for the poultry manure, goat manure and cow dung treated soil and 5.56, 5.81 and 5.84 respectively for the soil treated with poultry manure, goat manure and cow dung with PSB strain. Among the different treatments, soil treated with poultry manure + PSB strain showed the lowest $\mathrm{pH}$ at the end of the incubation period (Figure 04).

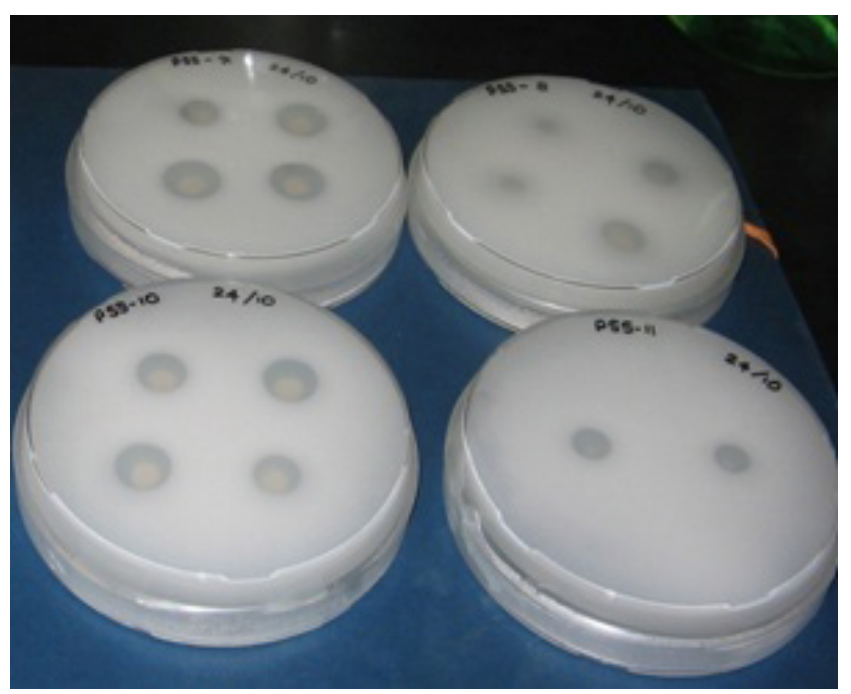

Figure 01: Isolated phosphate solubilizing bacterial strains showing clear halos produced in NBRIP solid medium 


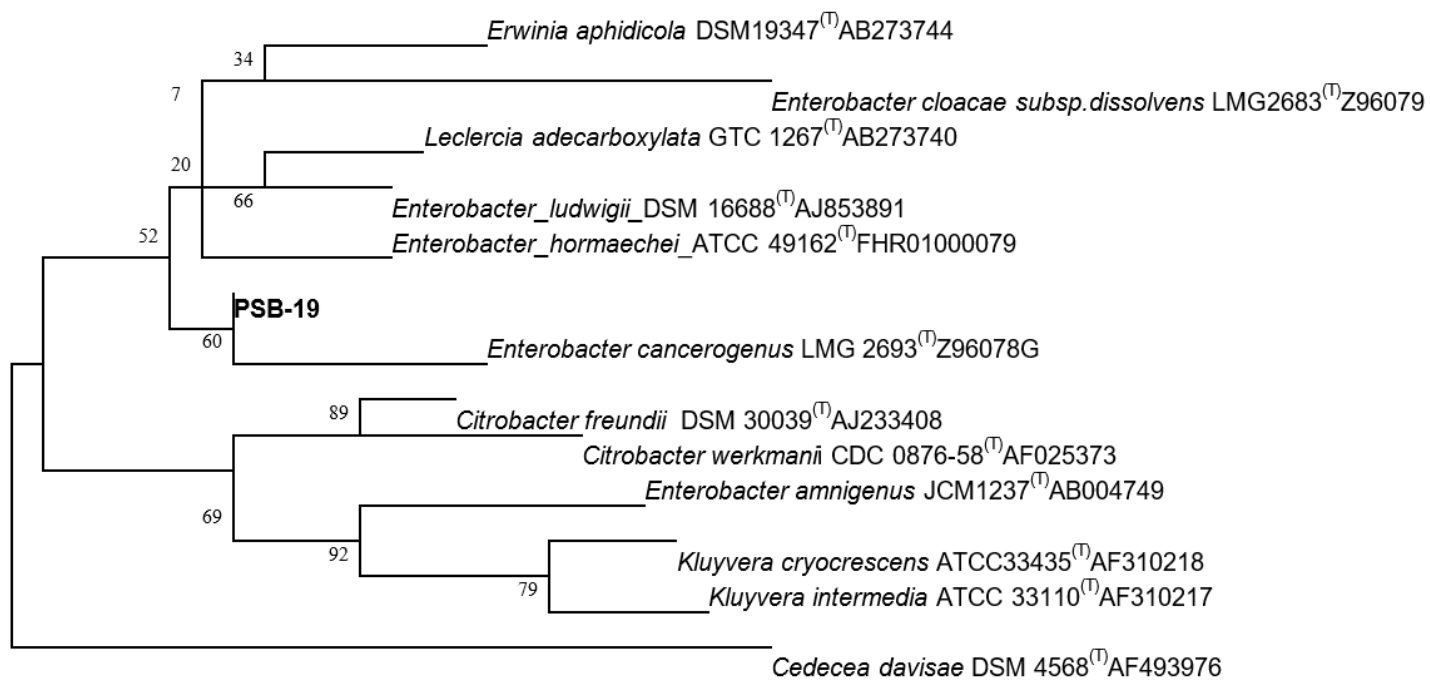

Figure 02: Phylogenetic tree based on 16S rRNA gene sequences, showing the position of Enterobacter cancerogenus (PSB-19) strain with respect to related species. The scale bar indicates 0.002 substitutions per nucleotide position and accession numbers are given in parenthesis.

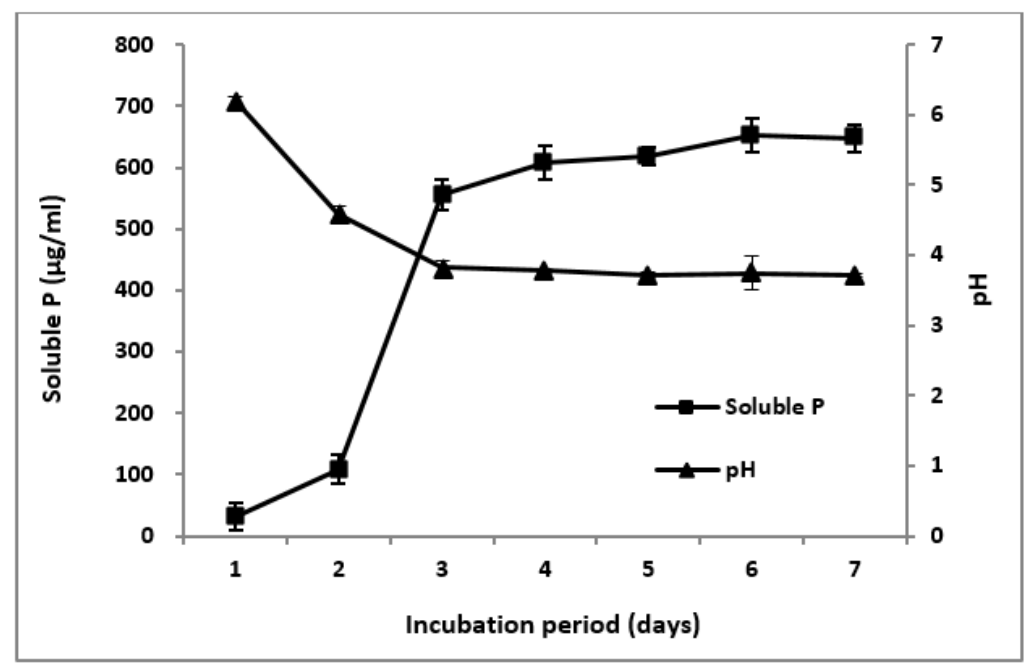

Figure 03: Insoluble Phosphate solubilization and changes of $\mathrm{pH}$ in NBRIP culture medium containing Enterobacter cancerogenus. Values given here are the means $(n=3) \pm$ standard deviation.

Table 03: Changes of the $\mathrm{pH}$ in the soil after application of organic amendments with and without PSB

\begin{tabular}{lccccccc}
\hline \multirow{2}{*}{ Treatments } & \multicolumn{7}{c}{ Days after treatment application } \\
\cline { 2 - 7 } & 7 & 14 & 21 & 28 & 35 & 42 & 56 \\
\hline Control & $6.43 \pm 0.22$ & $6.42 \pm 0.14$ & $6.41 \pm 0.12$ & $6.42 \pm 0.12$ & $6.4 \pm 0.17$ & $6.42 \pm 0.22$ & $6.44 \pm 0.21$ \\
Soil + PM & $6.33 \pm 0.18$ & $6.13 \pm 0.16$ & $6.11 \pm 0.17$ & $6.05 \pm 0.17$ & $6.02 \pm 0.15$ & $5.95 \pm 0.14$ & $5.85 \pm 0.17$ \\
Soil + GM & $6.34 \pm 0.15$ & $6.32 \pm 0.14$ & $6.21 \pm 0.15$ & $6.16 \pm 0.12$ & $6.04 \pm 0.12$ & $6.02 \pm 0.17$ & $5.96 \pm 0.12$ \\
Soil + CD & $6.22 \pm 0.15$ & $6.23 \pm 0.18$ & $6.19 \pm 0.26$ & $6.28 \pm 0.32$ & $6.26 \pm 0.11$ & $6.01 \pm 0.10$ & $5.95 \pm 0.12$ \\
Soil + PM + & $6.31 \pm 0.24$ & $6.13 \pm 0.22$ & $6.03 \pm 0.16$ & $5.94 \pm 0.12$ & $5.84 \pm 0.12$ & $5.78 \pm 0.25$ & $5.56 \pm 0.23$ \\
PSB & & & & & & & \\
Soil + GM + & $6.26 \pm 0.11$ & $6.21 \pm 0.12$ & $6.02 \pm 0.23$ & $6.01 \pm 0.22$ & $5.87 \pm 0.25$ & $5.82 \pm 0.26$ & $5.81 \pm 0.20$ \\
PSB & & & & & & & \\
Soil + CD + & $6.24 \pm 0.27$ & $6.21 \pm 0.19$ & $6.07 \pm 0.25$ & $5.86 \pm 0.21$ & $5.86 \pm 0.17$ & $5.85 \pm 0.15$ & $5.84 \pm 0.18$ \\
PSB & & & & & & & \\
Soil + PSB & $6.25 \pm 0.15$ & $6.25 \pm 0.23$ & $6.24 \pm 0.23$ & $6.31 \pm 0.26$ & $6.27 \pm 0.14$ & $6.23 \pm 0.16$ & $6.22 \pm 0.17$ \\
\hline
\end{tabular}




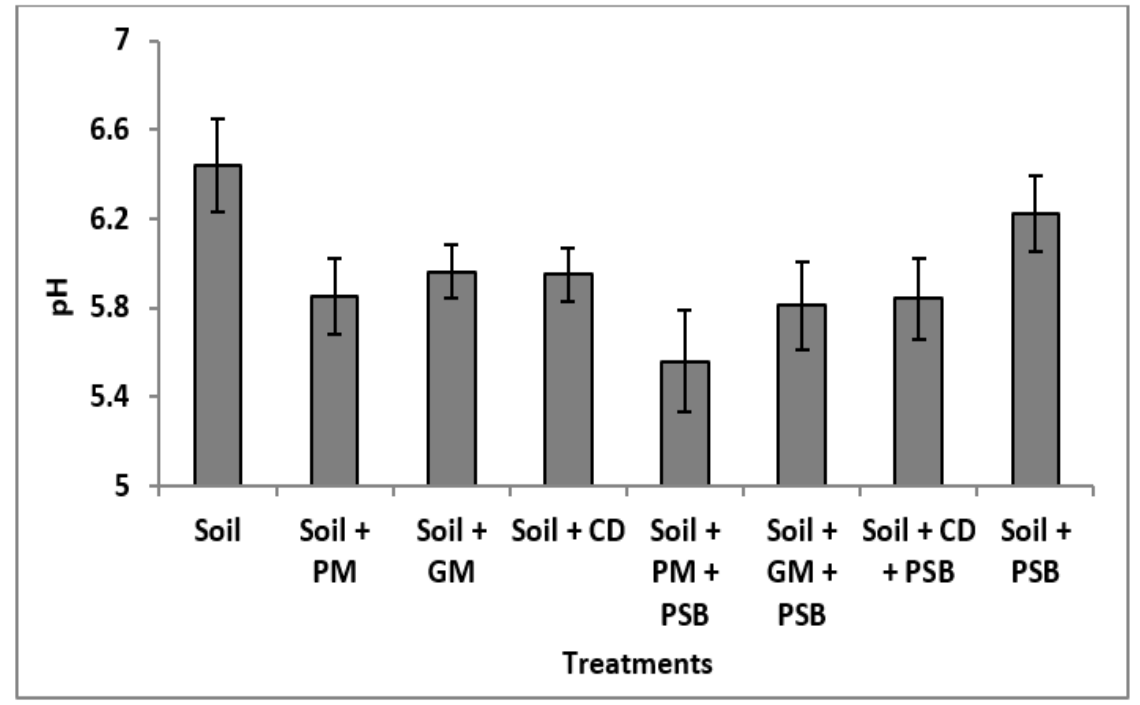

Figure 04: The final effect of different organic amendment on $\mathrm{pH}$ change

Table 04: The available soil phosphorous content in soil with and without PSB strain

\begin{tabular}{lccccccc}
\hline \multirow{2}{*}{ Treatments } & \multicolumn{7}{c}{ Days after treatment application (mg/kg soil) } \\
\cline { 2 - 8 } & 7 & 14 & 21 & 28 & 35 & 42 & 56 \\
\hline Control & $12.42 \pm 1.22$ & $16.58 \pm 1.52$ & $32.03 \pm 2.45$ & $29.35 \pm 2.73$ & $33.98 \pm 1.92$ & $34.54 \pm 2.12$ & $37.28 \pm 1.23$ \\
Soil + PM & $22.26 \pm 1.58$ & $32.55 \pm 2.51$ & $46.38 \pm 3.74$ & $51.44 \pm 3.73$ & $51.09 \pm 3.51$ & $50.32 \pm 3.25$ & $50.21 \pm 4.51$ \\
Soil + GM & $19.16 \pm 1.65$ & $22.02 \pm 1.64$ & $42.45 \pm 2.69$ & $42.13 \pm 2.51$ & $45.57 \pm 2.81$ & $43.14 \pm 2.86$ & $42.37 \pm 3.54$ \\
Soil + CD & $23.65 \pm 2.14$ & $27.6 \pm 2.84$ & $40.86 \pm 3.82$ & $48.52 \pm 2.68$ & $48.63 \pm 2.68$ & $48.45 \pm 2.84$ & $47.66 \pm 5.31$ \\
Soil + PM + & $36.19 \pm 2.67$ & $40.63 \pm 3.24$ & $54.43 \pm 3.62$ & $58.68 \pm 3.51$ & $63.66 \pm 3.54$ & $63.61 \pm 3.54$ & $62.24 \pm 2.94$ \\
PSB & & & & & & & $51.56 \pm 3.68$ \\
Soil + GM & $23.95 \pm 1.87$ & $27.34 \pm 1.82$ & $45.82 \pm 3.95$ & $53.85 \pm 3.62$ & $52.63 \pm 3.21$ & $52.32 \pm 2.94$ & 5 \\
+ PSB & & & & & & & \\
Soil + CD + & $14.21 \pm 1.93$ & $24.64 \pm 1.74$ & $45.73 \pm 2.57$ & $54.39 \pm 3.71$ & $55.05 \pm 2.62$ & $53.65 \pm 3.47$ & $53.34 \pm 3.54$ \\
PSB & & & & & & & \\
Soil + PSB & $10.53 \pm 1.57$ & $16.28 \pm 1.33$ & $34.41 \pm 2.63$ & $31.32 \pm 1.62$ & $36.72 \pm 2.46$ & $38.46 \pm 3.12$ & $39.61 \pm 2.52$ \\
\hline
\end{tabular}

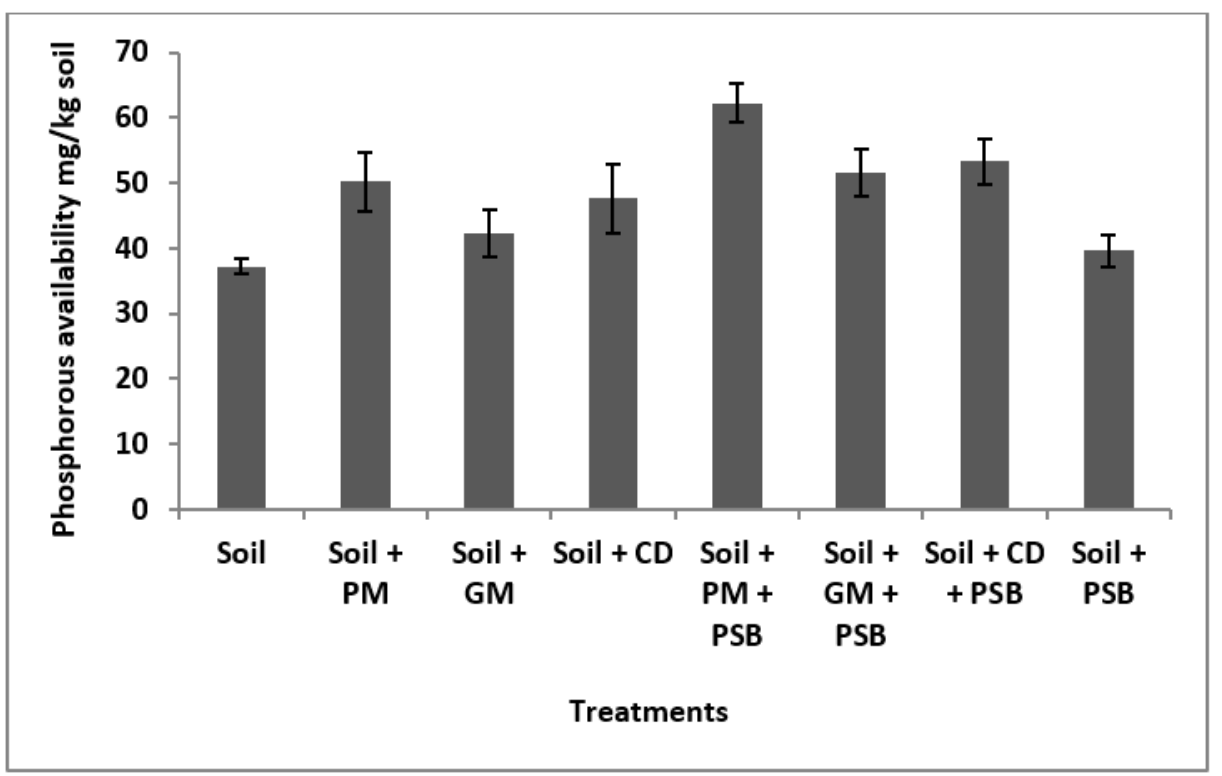

Figure 05: The final effect of different organic amendment on phosphorous availability 
The effect of different organic amendments with and without PSB strain on soil phosphorous availability over 8 weeks of incubation is presented in Table 04 and the overall effect of different amendments on soil phosphorous availability is presented in Figure 05. The phosphorous availability of organic manure amended soil (with and without PSB strain) was progressively increased and the bulk of the increment occurred during the first 2 to 3 weeks of the incubation. However, subsequently a slight reduction was observed during the later stage of the incubation. Phosphorous availability of the soil amended with the organic manure was significantly $(\mathrm{P} \leq 0.05)$ higher than that of the control. However, the figures were lower than that of the soil amended with organic manure + PSB strain. The application of PSB strain without organic amendments did not show any remarkable effect on phosphorous availability. Soil amended with PM + PSB strain showed the highest phosphorous availability throughout the incubation period.

The application and incorporation of organic amendment can result in an increase organic matter levels in soil. Several reports are available on the effects of organic matter in enhancing the availability of soil phosphorous (Kouno et al., 2002; Wu et al., 2007). Organic matter can have a synergistic effect on mineral phosphate availability in phosphorous fixing soils (Agbenin and Igbokwe, 2006; Gichangi and Mnkeni, 2009). The decomposition of organic amendment generate acidic environment by releasing organic anions. These organic anions can compete with phosphorous sorption sites and they enhance the chelation of soluble Al and reduce the precipitation and of Al-P. The density and diversity of soil microorganisms are increased when soils amended with organic amendments due to the fact that readily available substrates are released into the soil (Nishio and Kusano, 1980). Therefore, application of organic amendments to soil increase microorganism's density and diversity, organic anion production and help to increase phosphorous availability to plants by solubilizing insoluble phosphorous (Fankem et al., 2006; Hu et al., 2006).These findings are in agreement with the present results of increased soluble phosphorous content and decreased $\mathrm{pH}$ in organic manure amended soil during the incubation period (Table 01and 02). Reduction in soil $\mathrm{pH}$ after manure application has been reported by Abebe (2001) also. However, the range of $\mathrm{pH}$ reduction is found to be slightly varying (from 6.43 to 5.85 ) which might be due to high buffering capacity of the experimental soil as stated by Abu-Zahraand and Tahboub (2008).

Soil microorganisms are responsible for determining the status of organic matter decomposition, nutrient cycling, soil degradation and bioremediation of soil pollutants. They play a key role in making available soil phosphorous to plants by solubilizing and mineralizing organic and inorganic phosphorous sources (Xiao et al., 2013). Recently, emphasis has been paid to use of phosphate solubilizing bacteria in increasing the phosphorous efficiency thereby improving the growth and yield of crops. The major mechanisms involved in the phosphate solubilization by phosphate solubilizing microorganisms are acidification, chelation, ion exchange reactions and production of low molecular weight organic acids such as gluconic, oxalic and citric acids (Chaiharn and Lumyong, 2009; Ekin, 2010). Therefore, organic acid production contributes significantly to the process of acidification and $\mathrm{pH}$ reduction through which facilitates the phosphate solubilization. Present results of higher $\mathrm{pH}$ reduction and phosphate solubilization in soil amended with organic manure + PSB strain are therefore, in agreement with the early reports of Aria et al.,(2010) and Khanand Sharif, (2012), who conducted similar experiments with PSB inoculations. The effectiveness of different Enterobacter species in solubilizing phosphates have been identified previously also (Mirza et al.,2001; Deepa et al.,2010).

According to the results, the phosphorous availability of organic manure amended soil (with and without PSB strain) was found to be increased progressively and the bulk of the increment occurred during the first 2 to 3 weeks of the incubation. Simultaneously a rapid reduction in $\mathrm{pH}$ was observed during the period indicating that the acidification of the medium may have contributed to the enhanced 
solubilization of phosphates. Subsequent slight reduction of phosphorous availability observed during the later stages of the incubation might be due to the inhibitory effect caused by available phosphorous, formation of organo-phosphate compounds or depletion of nutrients especially carbon source for the microbial activity and production of organic acids as suggested by other researchers (Varsha-Narsian et al., 1994; Illmer and Schinner, 1995; Chaiharn and Lumyong, 2009). Phosphate solubilizing microorganisms are capable of utilizing a variety of carbon sources to meet their energy requirement. Therefore, the growth and phosphate solubilization of phosphate solubilizing microorganisms may vary with the carbon source. Carbon source is considered to be an important factor for active proliferation and organic acid production by the organisms. The nature of available carbon sources is thus decisive in determining the type and concentration of organic acid produced by the phosphate solubilizing microorganisms which in turn controls the degree of phosphate solubilization (Patel et al., 2008).

The overall effect of different organic amendments on $\mathrm{pH}$ and phosphate solubilization is shown in Figure 01 and 02. Poultry manure showed the highest $\mathrm{pH}$ reduction and phosphate solubilization compared to other treatments. In accordance with our results, Azeez and Van Averbeke (2012) also observed lowest $\mathrm{pH}$ values for poultry manure amended soil. The high phosphorous content in poultry manure could also contribute towards the high phosphorous concentration in soil after 56 days of incubation.

Similar to present findings, positive impacts of organic manure and PSB on phosphorous

\section{REFERENCES}

Abbasi, M. K., S. Mansha, N. Rahim,A. Ali(2013). Agronomic effectiveness and phosphorus utilization efficiency of rock phosphate applied to winter wheat. Agronomy Journal105: 1606-1612.DOI:https://doi.org/10.2134/agronj2012.0501

Abbasi, M. K., N. Musa,M. Manzoor (2015). Mineralization of soluble P fertilizers and insoluble rock phosphate in response to phosphate solubilizing bacteria and poultry manure and their effect on growth and $\mathrm{P}$ utilization efficiency of chilli (Capsicum annuum L.). Biogeosciences.12:4607-4619.DOI: https://doi.org/10.5194/bg-12-4607-2015 availability have been reported previously by Begum et al., (2004); Toor, (2009) and Abbasi et al., (2013). Production of organic acids from these organic manures and PSB strains in the root rhizosphere could reduce phosphorous fixation, induce greater P availability and form phosphorhumic complexes that are easily assimilated by plants (Toor, 2009). These mechanisms could ultimately result in converting greater amounts of applied $\mathrm{P}$ to available $\mathrm{P}$ in root rhizospere.

\section{ACKNOWLEDGMENT}

The authors are thankful to Faculty Research Grants, Faculty of Agriculture, University of Ruhuna and Graduate Studies Research Grants, Faculty of Graduate Studies, University of Ruhuna (RU/PG/R/15/02) for financial assistance.

\section{CONCLUSIONS}

Availability of soil phosphorous is enhanced by amendment with organic manure such as poultry manure, cow dung and goat manure with and without PSB. When applied with isolated PSB strain, greater phosphorous availability is resulted in poultry manure amended soils compared to other sources. However, further studies under field conditions are needed to applications. Economic feasibility of this application should also be quantified through a series of field trials. confirm the results and recommend commercial 
Abebe, G (2001). Effect of manure on some physico-chemical properties of calcareous soil, yield and quality of cowpea [Vigna unguiculata (L.) Walp.] Under greenhouse conditions. M.S. Thesis, University of Jordan, Amman, Jordan.

Abu-Zahraand T., A. B. Tahboub (2008). Effect of organic matter sources on chemical properties of the soil and yield of strawberry under organic farming conditions. World Applied Sciences Journal. 5:383-388.ISSN 1818-4952

Adesanwo, O. O., M. T. Adetunji,S. Diatta (2012). Effect of legume incorporation on solubilization of Ogun phosphate rock on slightly acidic soils in SW Nigeria. Journal of Plant Nutrition and Soil Science175: 377-384.DOI: https://doi.org/10.1002/jpln.201000361

Agbenin, J.O., S.O. Igbokwe (2006). Effect of soil- dung manure incubation on the solubility and retention of applied phosphate by a weathered tropical semi-arid soil. Geoderma. 133:191203.DOI: https://doi.org/10.1016/j.geoderma.2005.07.006

Aria, M. M., A. Lakzian, G. H. Haghnia, A. R. Berenji, H. Besharati,A. Fotovat (2010). Effect of Thiobacillus, sulfur, and vermicompost on the water-soluble phosphorus of hard rock phosphate. Bioresource Technology 10: 551-554.DOI: https://doi.org/10.1016/j. biortech.2009.07.093

Azeez, J.O., W. Van Averbeke (2012) Dynamics of soil pH and electrical conductivity with the application of three animal manures. Communications in Soil Science and Plant Analysis. 43: 865-874. DOI: https://doi.org/10.1080/00103627509366539

Begum, M., G. Narayanasamy,D. R. Biswas (2004). Phosphorus supplying capacity of phosphate rocks as influenced by compaction with water-soluble $\mathrm{P}$ fertilizers. Nutrient Cycling in Agroecosystems 68: 73-84.DOI:https://doi.org/10.1023/B:FRES.0000012237.35121.6f

Chaiharn, M., S. Lumyong (2009). Phosphate solubilization potential and stress tolerance of rhizobacteria from rice soil in Nothern Thailand. World Journal of Microbiology and Technology 25: 305 - 314.DOI: https://doi.org/10.1007/s11274-008-9892-2

Deepa, C. K., S. G. Dastager, A. Pandy (2010). Isolation and characterization of plant growth promoting bacteria from non-rhizospheric soil and their effect on cowpea (Vigna unguiculata (L.) Walp.) seedling growth. World Journal of Microbiology and Technology26: 1233-1240. DOI: https://doi.org/10.1007/s11274-009-0293-y

Ekin, Z (2010). Performance of phosphate solublizing bacteria for improving growth and yield of sunflower (Helianthus annus L.) in the presence of phosphorous fertilizer. African Journal of Biotechnology 9: 3794-3800.http://www.academicjournals.org/AJB

Fankem, H., D. Nwaga, A. Deubel, L.Dieng, W. Merbach,F. X. Etoa (2006). Occurrence and functioning of phosphate solubilizing microorganisms from oil palm tree (Elaeis guineensis) rhizosphere in Cameroon. African Journal of Biotechnology5: 2450-2460.http://www. academicjournals.org/AJB

Gichangi, E. M., P. N. S. Mnkeni (2009). Effects of goat manure and lime addition on phosphate sorption by two soils from the Transkei Region, South Africa. Communications in Soil Science and Plant Analysis. 40:3335-3347.DOI: https://doi.org/10.1080/00103620903325943 
Gyaneshwar, P., L. J. Parekh, G. Archana, P. S. Poole, M. D. Collins, R. A. Hutson, N. Kumar G (1999). Involvement of a phosphate starvation inducible glucose dehydrogenase in soil phosphate solubilization by Enterobacter asburiae. FEMS Microbiology Letters. 171: 223229. DOI: https://doi.org/10.1111/j.1574-6968.1999.tb13436.x

Hu, X., J. Chen,J. Guo (2006). Two phosphate and potassium solubilizing bacteria isolated from Tianmu Mountain, Zhejiang, China. World Journal of Microbiology and Biotechnology22: 983-990.DOI: https://doi.org/10.1007/s11274-006-9144-2

Illmer, P.,F. Schineer (1995). Solubilization of inorganic calcium phosphates solubilization mechanisms. Soil Biology and Biochemistry 27:257-263. DOI: https://doi.org/10.1016/00380717(94)00190-C

Imran, M., R.Waqas, Z. I. H. Nazli, B. Shaharoona,M.Arshad (2011). Effect of recycled and valueadded organic waste on solubilization of rock phosphate in soil and its influence on maize growth. International Journal of Agriculture and Biology13: 751-755.DOI: https://doi. org/10-701/AWB/2011/13-5-000-000

Khan, M. S., A. Zaidi, E. Ahmad (2014). Mechanism of phosphate solubilization and physiological functions of phosphate solubilizing microorganisms, In: Phosphate Solubilizing Microorganisms: Principles and application of microphos technology (eds. M. S. Khan, A. Zaidi, \& J. Musarrat), pp. 31-62. Springer International Publishing Switzerland, Switzerland.

Kouno, K., J. Wu, P. C. Brookes (2002). Turnover of biomass C and P in soil following incorporation of glucose and ryegrass. Soil Biology and Biochemistry 34: 617-622. DOI:https://doi. org/: 10.1016/S0038-0717(01)00218-8

Kumar, S., K. Tamura, I. B. Jakobsen,M. Nei (2001). MEGA2: molecular evolutionary genetics analysis software. Bioinformatics17:1244-1245.DOI:https://doi.org/10.1093/ bioinformatics/17.12.1244

Mapa, R. B., S. Somssiri,S. Nagarajah (1999). Soils of the wet zone of Sri Lanka. Soil Science Society of Sri Lanka. Sri Lanka. pp 23-92.

Mirza, M. S., W. Ahmad, F. Latif, J. Haurat, R. Bally, P. Normand,K. A. Malik (2001). Isolation, partial characterization, and the effect of plant growth promoting bacteria (PGPB) on micro-propagated sugarcane in vitro. Plant and Soil237:47-54.DOI: https://doi. org/10.1023/A:1013388619231

Murphy, J. J. P. Riley (1962). A modified single solution method for the determination of phosphate in natural waters. Analytica Chimica Acta27:31-36. DOI: https://doi.org/10.1016/S00032670(00)88444-5

Nautiyal, C. S.(1999). An efficient microbiological growth medium for screening phosphate solubilizing microorganisms. FEMS Microbiology Letters 170: 265-270. DOI:https://doi. org/10.1111/j.1574-6968.1999.tb13383.x

Nishanth, D.,D. R. Biswas (2008). Kinetics of phosphorus and potassium release from rock phosphate and waste mica enriched compost and their effect on yield and nutrient uptake by wheat (Triticum aestivum). Bioresource Technology 99: 3342-3353.DOI: https://doi. org/10.1016/j.biortech.2007.08.025 
Patel, D. K., G. Archana,N. Kumar (2008). Variation in the nature of organic acid secretion and mineral phosphate solubilization by Citrobacter sp. DHRSS in the presence of different sugars. Current Mcrobiology56:168-174.DOI:https://doi.org/10.1007/s00284-007-9053-0

Saitou, N.,M.Nei (1987). The neighbor-joining method: a new method for reconstructing phylogenetic trees. Molecular Biology and Evolution4:406-425.DOI: https://doi.org/10.1093/ oxfordjournals.molbev.a040454

SAS(1999). SAS/STAT User's Guide Version 8. SAS, Cary, NC.

Thompson J. D., T. J. Gibson, F. Plewniak, F. Jeanmougin,D. G.Higgins(1997). The CLUSTAL $\mathrm{X}$ windows interface: flexible strategies for multiple sequence alignment aided by quality analysis tools. NucleicAcids Research25:4876-4882.DOI: https://doi.org/10.1093/ nar/25.24.4876

Toor, G. S. (2009). Enhancing phosphorus availability in low-phosphorus soils by using poultry manure and commercial fertilizer. Soil Science174: 358-364, 2009.DOI: https://doi. org/10.1097/SS.0b013e3181a7e716

Varsha-Narsian, J., J. Thakkar,H. H. Patel(1994). Inorganic phosphate solubilization by some yeast. Indian Journal of Microbiology 35: 113-118.DOI: https://doi.org/10.1007/s12088009-0019-8

Walpola B.C.,M. H. Yoon (2012). Prospectus of phosphate solubilizing microorganisms and phosphorous availability in agricultural soils: A review. African Journal of Microbiology research, 6: 6600-6605. DOI: https://doi.org/ 10.5897/AJMR12.889

Wickramatilake, A. R. P., K. Kouno,T. Nagaoka (2010). Compost amendment enhances the biological properties of Andosols and improves phosphorus utilization from added rock phosphate. Soil Science and Plant Nutrition56: 607-616.DOI: https://doi.org/10.1111/ j.1747-0765.2010.00493.x

Wu, J., M. Huang, H. A. Xiao, Y. R. Su (2007). Dynamics in microbial immobilization and transformation of phosphorus in highly weathered subtropical soil following organic amendments. Plant Soil 290: 333-342. DOI: https://doi.org/ 10.1007/s11104-006-9165-5

Xiao, C, Q., H. X. Zhang, Y. J. Fang, R. A. Chi (2013). Evaluation for rock phosphate solubilization in fermentation and soilplant system using a stress-tolerant phosphate-solubilizing Aspergillus niger WHAK1. Applied Biochemistry and Biotechnology 169:123-133. DOI: https://doi. org/10.1007/s12010-012-9967-2

Zaidi, A., M.S. Khan M.Ahemad,M. Oves (2009). Plant growth promotion by phosphate solubilizing bacteria. Acta Microbiologica et Immunologica Hungarica56: 263-284.DOI: https://doi.org/10.1556/AMicr.56.2009.3.6. 